
October 1944

\title{
HEATS OF COMBUSTION OF EIGHT NORMAL PARAFFIN HYDROCARBONS IN THE LIQUID STATE
}

\author{
By Edward J. Prosen and Frederick D. Rossini
}

\section{ABSTRACT}

The heats of combustion of $n$-pentane, $n$-hexane, $n$-heptane, $n$-octane, $n$-nonane' $n$-decane, $n$-dodecane, and $n$-hexadecane, in the liquid state, were measured with a bomb calorimeter. The samples of hydrocarbon were of known high purity, were inclosed in thin glass bulbs and placed in a platinum cup in the calorimetric bomb with purified oxygen at a pressure of $30 \mathrm{~atm}$, and were ignited electrically with a wire fuse. The amount of reaction in each experiment was determined from the amount of carbon dioxide formed by the combustion. Tests were made for the presence of carbon monoxide and other products of incomplete combustion. The calorimeter system was calibrated with electrical energy.

From the experimental data were calculated the following values for the heat of combustion, at $25^{\circ} \mathrm{C}$ and constant pressure, of the liquid hydrocarbon in gaseous oxygen to form gaseous carbon dioxide and liquid water, with all the reactants and products in their thermodynamic standard reference states, in int. $\mathrm{kj} / \mathrm{mole}: n$-pentane, $3508.56 \pm 0.77 ; n$-hexane, $4162.34 \pm 0.83 ; n$-heptane, $4816.35 \pm 0.87 ; n$-octane, $5469.82 \pm 1.05 ; n$-nonane, $6123.90 \pm 1.12 ; n$-decane, $6777.47 \pm 1.52 ; n$-dodecane, $8085.20 \pm 1.65 ; n$-hexadecane, $10699.1 \pm 2.8$. The corresponding values in $\mathrm{kcal} / \mathrm{mole}$, obtained by using the factor $1 / 4.1833$, are $n$-pentane, $838.71 \pm 0.18 ; n$-hexane, $994.99 \pm 0.20 ; n$-heptane, $1151.33 \pm 0.21$ $n$-octane, $1307.54 \pm 0.25 ; n$-nonane, $1463.89 \pm 0.27 ; n$-decane, $1620.13 \pm 0.36$; $n$-dodecane, $1932.73 \pm 0.39 ; n$-hexadecane, $2557.58 \pm 0.68$.

\section{CONTENTS}

I. Introduction

II. Unit of energy, molecular weights, etc

III. Method _.....

IV. Materials, chemical apparatus, and procedure

1. Source and purity of the hydrocarbons _............ 257

2. Sealing of the hydrocarbons in glass ampoules

3. Purification of the oxygen used for combustion

4. Examination of the products of combustion

5. Determination of the amount of reaction ............ 259

6. Absorption tubes for weighing _._.

V. Calorimetric apparatus.

1. Calorimeter assembly

2. Combustion bomb

3. Power-measuring apparatus

4. Timing device

5. Thermometric system

VI. Calorimetric procedure

1. Experiments with electrical energy

2. Determination of the ignition energy

3. Combustion experiments _...

4. Correction for the formation of nitric acid 
VIII. Page

VII. Results of the present investigation

1. Experiments with electrical energy

2. Combustion experiments .

3 . Values of the heats of combustion

VIII. Discussion _.

IX. References_... 272

\section{INTRODUCTION}

In continuation of the work of the thermochemical laboratory of this Bureau in determining the thermochemical constants of substances, the heats of combustion of $n$-pentane, $n$-hexane, $n$-heptane, $n$-octane, $n$-nonane, $n$-decane, $n$-dodecane, and $n$-hexadecane, in the liquid state, were measured. This paper describes in detail the calorimetric and chemical apparatus and procedure and gives the experimental data obtained.

\section{UNIT OF ENERGY, MOLECULAR WEIGHTS, ETC.}

The unit of energy upon which the experimental values of this investigation are based is the international joule determined by the standards of resistance (international ohms), electromotive force (international volts), and time (mean solar seconds) maintained at this Bureau.

For the conversion of values in international joules to values expressed in terms of the conventional thermochemical calorie, the following relation is used [1] : ${ }^{1}$

\subsection{3 international joules $(\mathrm{NBS})=1$ calorie.}

The molecular weight of carbon dioxide, the mass of which was used to determine the amount of reaction, was taken as 44.010, from the 1941 table of International Atomic Weights [2].

The uncertainties assigned to the various quantities dealt with in this paper were derived, where possible, by a method previously described [3]. In other cases, reasonable estimates of the uncertainty were made.

\section{METHOD}

The method is the substitution method, in which the heat evolved by a measured amount of chemical reaction is compared with the heat evolved by a measured amount of electrical energy, with the calorimeter system serving as the absorber and comparator of the two kinds of energy. A standard calorimeter system was used and the temperature rise was made substantially the same in all experiments.

The energy equivalent of the calorimeter is determined in a series of experiments with electrical energy. The relation used in computing the energy equivalent of the calorimeter $E_{s}$, is

$$
E_{s}=f Y / \Delta R_{y}
$$

where $Y$ is the observed electrical energy; $f$ is a constant whose value is the resultant of the various calibration factors associated with the instruments used in measuring the electrical energy, such as the stand-

1 Figures in brackets indicate the literature references at the end of this paper. 
ard resistances, standard cell, resistance coils of the potentiometer, timing apparatus, etc., and $\Delta R_{y}$ is the rise in temperature measured as an increase in resistance in ohms of the given platinum resistance thermometer at the given mean temperature. The product $f Y$ gives the electrical energy in terms of the unit fixed by the units of resistance, electromotive force, and time. In the present experiments this unit is the international joule.

The amount of chemical reaction that produces, in the calorimeter, a rise in temperature substantially equal to that in the experiments with electrical energy is determined in a series of calorimetric reaction experiments. The relation used in reducing the data of these experiments is

$$
B^{\prime}=B / g=\Delta R_{v} / W g,
$$

where $W$ is the observed mass of the substance (in the present experiments, carbon dioxide) that is used to determine the amount of reaction, $g$ is a factor whose value is the resultant of the various factors required to convert the observed mass of the carbon dioxide to the number of moles of the desired pure reaction $\Delta R_{w}$ is the rise in temperature measured as an increase in resistance in ohms of the given platinum resistance thermometer at the given mean temperature, and $B$ is a constant representing the temperature (expressed in ohms) per unit mass of the selected substance, carbon dioxide, that determines the amount of reaction.

The experimental value of the heat evolved per mole of the reaction being studied is

$$
Q=E_{\mathrm{g}} B^{\prime}=\left(Y / \Delta R_{y}\right)\left(\Delta R_{w} / W\right)(f / g) .
$$

The ratios $Y / \Delta R_{y}$ and $\Delta R_{v} / W$ are evaluated in the electrical energy experiments and the chemical reaction experiments, respectively, and the ratio $\mathrm{f} / \mathrm{g}$ includes all the constant factors involved in the reduction of the data.

In the present investigation, the over-all uncertainty assigned to any final value $Q$ was taken as the combination (square root of the sum of the squares) of an uncertainty of 0.010 percent in $f, 0.010$ percent in $g$, twice the standard deviation of the mean of the series of experiments made to evaluate $Y / \Delta R_{y}$, and twice the standard deviation of the mean of the series of experiments made to evaluate $\Delta R_{w} / W$.

\section{MATERIALS, CHEMICAL APPARATUS, AND PROCEDURE}

\section{SOURCE AND PURITY OF THE HYDROCARBONS}

$n$-Pentane.-The material used in series I and II and in two exper ments of series III was from some purified material prepared by the American Petroleum Institute Research Project 6 at this Bureau for the determination of physical properties and was found by A. R. Glasgow, Jr., from time-temperature freezing and melting curves [12], to have $0.0014 \pm 0.0007$ mole fraction of impurity. The material used in two other experiments of series III was from the lot synthesized by Mair [13]. From the value of the freezing point reported by him, and the 
value for $n$-pentane of zero impurity [12], the amount of impurity in the latter sample was estimated to be less than 0.0010 mole fraction.

$n$-Hexane. - The material used in the experiments of series I and series III is the same as lot I, and for the experiments of series II the same as lot II, described in the authors' report on the isomeric hexanes [4]. From the value of the freezing point reported by Mair [13], and the value for $n$-hexane for zero impurity [12], the amount of impurity in the $n$-hexane used in experiments of series II was estimated to be $0.0010 \pm 0.0006$ mole fraction.

$n$-Heptane.-The material used in the experiments of series I and II was the same as that described in the report on the isomeric heptanes [15]. The amount of impurity in the $n$-heptane used in the experiments of series III was determined by A. R. Glasgow, Jr., from time-temperature freezing and melting curves [12] to be 0.0012 \pm 0.0006 mole fraction. This material was purified by the API Research Project 6 at this Bureau for the determination of physical properties.

n-Octane.-The lot of material used in the experiments of series I and that used in the experiments of series II were from material synthesized by the API Hydrocarbon Research Project at the Ohio State University. ${ }^{2}$ These two lots of $n$-octane were found by A. R. Glasgow, Jr., from freezing-point measurements, to have, respectively, $0.0080 \pm 0.0010$ and $0.0035 \pm 0.0005$ mole fraction of impurity.

$n$-Nonane and $n$-decane.-These materials were from the lots synthesized by Mair [13]. From the values of the freezing points reported by him, and the values for $n$-nonane and $n$-decane of zero impurity [12], the amounts of impurity in these samples were estimated to be $0.007 \pm 0.002$ and $0.0006 \pm 0.0004$ mole fraction, respectively.

$n$-Dodecane.-This material was from the best lot isolated from petroleum by Mair and Streiff [14], who reported the amount of impurity to be less than 0.0006 mole fraction.

$n$-Hexadecane.-This material was purified by crystallization and adsorption by A. J. Streiff and B. J. Mair from material supplied by the E. I. du Pont de Nemours Co. ${ }^{3}$ From the value of the freezing point, determined by A. R. Glasgow, Jr., the amount of impurity in this sample was determined to be $0.040 \pm 0.004$ mole fraction. From the manner of purification, it would be expected that the impurities in the $n$-hexadecane would be pentadecanes, hexadecanes, and heptadecanes. With the amount of reaction being determined from the mass of carbon dioxide formed in the combustion, it can be calculated that this apparently large amount of impurity in the $n$-hexadecane would not affect the heat of combustion by more than 1 or 2 parts in 10,000 . On account of this impurity, an additional uncertainty of 0.02 percent is carried into the over-all uncertainty assigned to the value of the heat of combustion for $n$-hexadecane.

The amounts of impurity in the samples of $n$-pentane, $n$-hexane, $n$-heptane, $n$-octane, $n$-nonane, $n$-decane, and $n$-dodecane are such that they would affect the value of the heat of combustion by less than 5 parts in 100,000 . This conclusion is based on the fact that the manner of preparation and purification of these compounds was

\footnotetext{
These materials were made available by C. E. Boord, supervisor of that project, and George Calingaert , chairman of the Subcommittee on Physical Properties.

3 This material was made available by Don M. Smith.
} 
such that the small amounts of impurities remaining would be largely isomeric.

\section{SEALING OF THE HYDROCARBONS IN GLASS AMPOULES}

The hydrocarbons were sealed in glass ampoules, prior to com. bustion in the bomb, in the manner described in detail in the previous report [4].

\section{PURIFICATION OF THE OXYGEN USED FOR COMBUSTION}

The oxygen used for the combustion of the hydrocarbons was ordinary commercial oxygen, which was freed of combustible impurities by passage through hot copper oxide, using the apparatus and procedure previously described for this purpose [4].

\section{EXAMINATION OF THE PRODUCTS OF COMBUSTION}

The products of combustion were examined to determine the amount of carbon dioxide formed in the main reaction of combustion in the bomb, the amount of nitric acid formed by oxidation of some of the nitrogen in the oxygen used for combustion, and the amount of carbon dioxide formed by subsequent oxidation of any products of incomplete combustion. In only one experiment (on n-octane) was there found any evidence of incomplete combustion. The apparatus and procedure previously described [4] were used.

\section{DETERMINATION OF THE AMOUNT OF REACTION}

For each calorimetric combustion experiment, the amount of reaction was determined from the mass of carbon dioxide formed, taking 1 mole $(44.010 \mathrm{~g}$ ) of carbon dioxide as equal to $1 / n$ moles of the given hydrocarbon, $n$ being the number of carbon atoms per molecule. The same apparatus and procedure were used as before, except that, in the later experiments, a new form of absorption tube was used, as described below.

\section{ABSORPTION TUBES FOR WEIGHING}

The new absorption tube ${ }^{4}$ used in the latter part of this investigation is shown in figure 1. The gas enters at the left, passes downward through the body of the tube, which contains, in order, Ascarite, anhydrous magnesium perchlorate, and phosphorus pentoxide, separated by layers of dry, shredded asbestos. The gas leaves the body of the tube at the bottom, passes upward through the side tube, reenters and passes through the cap through a right-angle tube and leaves at the right. The tube is closed by turning the cap one-eighth turn in either direction. The advantages of this tube over the conventional U-tube for this type of work are (a) greater compactness, (b) greater ease in lining up two tubes in series in an analytical train, and (c) presence of only one lubricated ground joint. As used in this investigation in the manner described above, the new tube had the disadvantage that it was more difficult to clean after being used to

- See also reference [11]. 


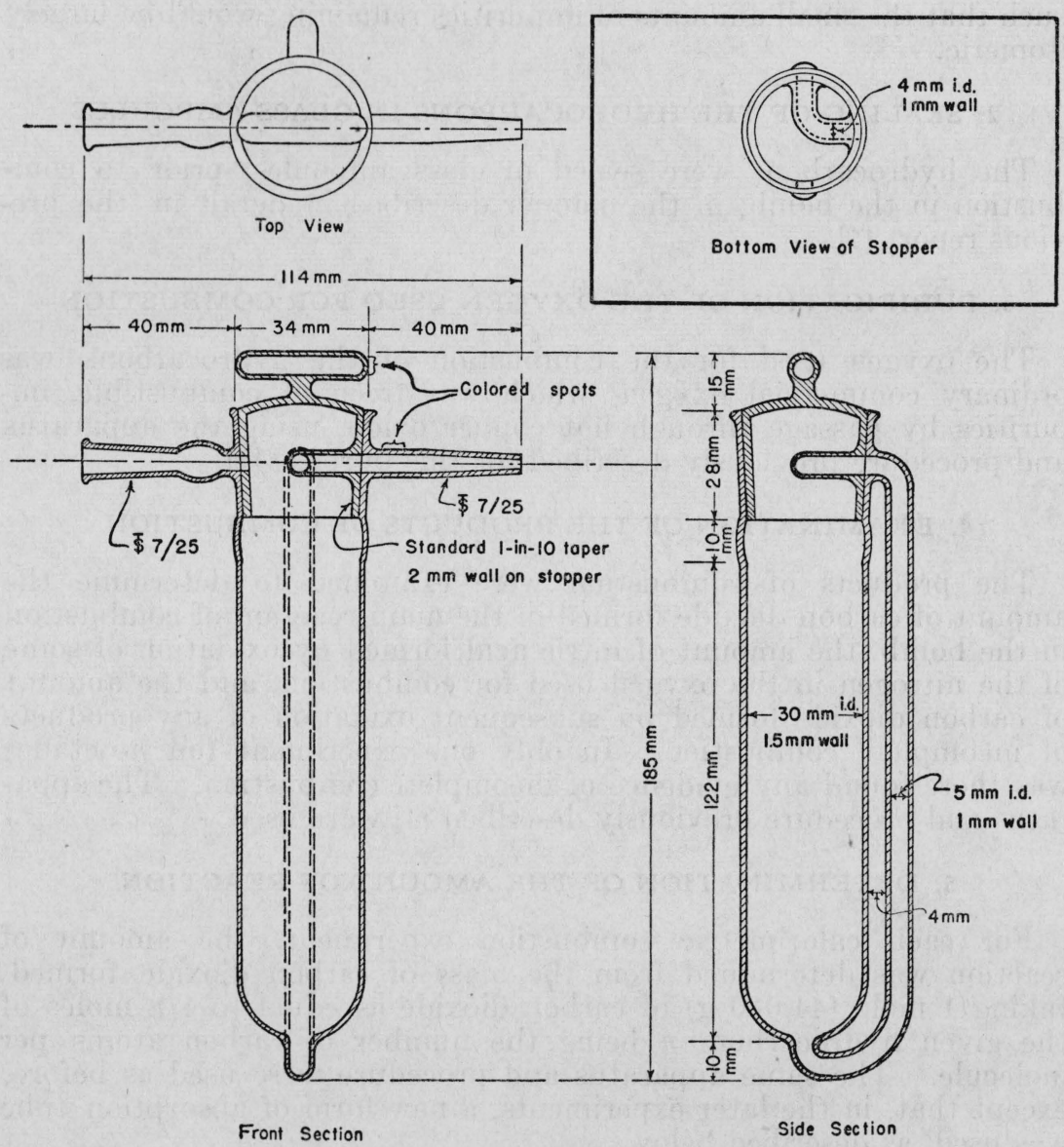

Figure 1.-Absorption tube.

(See text for explanation.)

absorb carbon dioxide. The Ascarite becomes hard after such absorption, and when it was placed at the top of the tube, it was necessary to dig a hole through it to remove the loose phosphorus pentoxide and magnesium perchlorate before the Ascarite is dissolved away with water. This one disadvantage has subsequently been eliminated by placing the absorbents in the absorption tube in the reverse order and passing the gas through in the opposite direction.

\section{CALORIMETRIC APPARATUS}

\section{CALORIMETER ASSEMBLY}

The calorimeter system was the same as that used in the previous investigation [4]. Some minor changes in the physical part of the system were made during the course of the investigation, which resulted in four slightly different calorimeter systems, $A, B_{1}, B_{2}$, and $C$, with the energy equivalents of systems $B_{1}$ and $B_{2}$ being substan- 
tially identical. (See section VII-1 of this paper.) The calorimeter heater used in the experiments with system $B_{2}$ and system $C$ was the one described on page 293 of reference [4] and was tightly fitting on the bomb body. The calorimeter heater used in the experiments with system $A$ and with system $B_{1}$ was of the same design as the foregoing, except that the diameter of the cylinder was $9.0 \mathrm{~cm}$ instead of $7.8 \mathrm{~cm}$, and the heater fitted loosely on the bomb body.

The rate of stirring of the calorimeter was $285 \mathrm{rpm}$ in all the experiments with system $A$ and system $B_{1}$ and was $350 \mathrm{rpm}$ in all the remaining experiments, except where stated differently in table 1.

\section{COMBUSTION BOMB}

The combustion bomb described in reference [4] was used in all the experiments except those with the calorimeter system $A$, in which a bronze sleeve with 10 steel setscrews was used instead of the stainlesssteel sleeve with 16 setscrews shown as $C$ in figure 1 on page 294 of reference [4]. The stainless-steel sleeve was found to be superior from the standpoint of providing more easily a tight closure of the bomb head on the body. Leakage of gas from the bomb at the time of explosion was tested for in a number of experiments throughout the investigation.

\section{POWER-MEASURING APPARATUS}

The electrical power was computed as the product of the potential drop per ohm across a $0.1-\mathrm{ohm}$ standard resistor in series with the calorimeter heater and the potential drop across the calorimeter heater, corrected for the current through the standard resistors in parallel with the calorimeter heater. The potential drop across the latter was determined from the potential drop across a $10-\mathrm{ohm}$ standard resistor in series with two 10,000 -ohm standard resistors, all of which were in parallel with the calorimeter heater. All the standard resistors were calibrated at intervals of about 1 year by the Resistance Measurements Section of this Bureau.

The potential drops were measured with a White double potentiometer, using saturated standard cells maintained at a constant temperature of $30^{\circ} \mathrm{C}[5,6]$. These cells were made by the Electrochemistry Section of this Bureau and calibrated by them at intervals of about 1 year.

The potentiometer was calibrated by the Electrical Division of this Bureau in 1936, 1942, and 1943. From experiments with electrical energy performed at various times during 1939, 1940, and 1941, a seasonal variation of the apparent energy equivalent of the calorimetric system was found. The magnitude of this variation was equivalent to a maximum variation of 9 in 100,000 in the resistance coils of the potentiometer, if it is assumed that the other parts of the measuring system did not change. The results of the experiments with electrical energy were corrected on the basis of this assumption and the results of the calibration of the potentiometer.

Although the assumption that the parts of the system other than the potentiometer did not change may not be strictly correct, it is consistent with the results of the calibrations of the potentiometer. Also, there are reasons for believing that the high-resistance coils of the potentiometer are affected by varying humidity to a greater ex- 
tent than are the other parts of the system $[9,18]$. The above method of correcting the results of the experiments with electrical energy is believed to be justified in view of these facts, and in view of the small magnitude of the observed variation in energy equivalent. Recently, the procedure was adopted of checking the potentiometer ratio at the time of each experiment with electrical energy, using two known standard resistors and an auxiliary battery [7].

The entire electrical measuring system was shielded, with copper sheets under the instruments, calorimeter, etc., and with a ground connection to one of the battery leads outside of the measuring circuit, such that the potential difference between the leads to the potentiometer and the ground was as small as possible.

\section{TIMING DEVICE}

The timing device for determining the time of input of the electrical power was the same as that used in the previous investigations in this laboratory [8]. The current was kept flowing through an external coil of the same resistance as the calorimeter heater. At the appropriate instant, the current was switched into the calorimeter heater and then, at the end of the given time, back to the external "spill" coil. A correction was appropriately applied to the power measurements because of the slightly different resistance of the timing switch circuit during the first two seconds and the last two seconds of the heating from its resistance during the main part of the heating period (see section VI-1). Although negligible (3 parts per million), this correction was made for the sake of completeness.

\section{THERMOMETRIC SYSTEM}

In the experiments with calorimeter systems $A$ and $B$, platinum resistance thermometer No. 285,380 was used [4], whereas in the experiments with calorimeter system $C$ a new platinum resistance thermometer No. 373,730 was used. The constants provided for this thermometer by the Thermometry Section of this Bureau yield the following relation for the range $0^{\circ}$ to $100^{\circ} \mathrm{C}$ :

and

$$
R=25.5170+0.101615 t-0.00001492 t^{2} \text { int. ohms }
$$

$$
d R / d t=0.101615-0.00002984 t \text { int. ohm/degree. }
$$

The foregoing equations are used only to determine the temperature to which the observed thermodynamic quantity is to be assigned. A knowledge of the actual relation between resistance and temperature for a given thermometer is not needed for the comparison of electrical energy and chemical energy when the experiments are performed over the same interval of resistance at the same mean temperature.

ates [5].

The resistance bridge used was the same as that"previously described 


\section{CALORIMETRIC PROCEDURE}

\section{EXPERIMENTS WITH ELECTRICAL ENERGY}

The procedure followed in performing an experiment with electrical energy was as follows: The fuse wire, $0.20 \mathrm{~g}$ of soft glass, and $1.00 \mathrm{ml}$ of water were placed in the bomb body and the bomb was closed. The bomb was flushed with purified oxygen to remove the air, the exit valve was closed, and the bomb was filled with oxygen to a pressure of $30 \mathrm{~atm}$ at $25^{\circ} \mathrm{C}$. The standard mass of water $(2,873.26 \pm 0.02$ g) was weighed in the calorimeter can, which was then placed in position in the calorimeter. The heating coil was placed in position on the bomb body, which was then carefully lowered into the calorimeter can. The latter was then covered with its lid.

The temperature of the jacket was maintained at $28.02^{\circ} \mathrm{C}$, constant within $\pm 0.002^{\circ} \mathrm{C}$. The experiments were begun with the temperature of the calorimeter near $25.00^{\circ} \mathrm{C}$, and the final temperature was made to be slightly below that of the jacket. In the fore period of 20 minutes, readings of the calorimeter temperature were taken every 2 minutes. During the second preceding the end of the 20th minute, the switches on the automatic switching device were set so that the current would be changed from the external stabilizing or "spill" coil to the calorimeter heater when the time signal at 20:00 minutes clicked. At 20:02 the timing device switches were changed from the "temporary" to the "permanent" setting, with no interruption to the flow of current. During the heating period of 5 minutes, readings were taken every minute of the resistance of the platinum thermometer in the calorimeter, the "voltage," and the "current." At 24:58, 2 seconds before the end of the 5-minute heating period, the switches of the timing device were changed from their "permanent" to their "temporary" setting, and at 25:00 the current was automatically changed from the calorimeter heater to the external stabilizing coil. ${ }^{5}$ Readings of the resistance of the platinum thermometer were then taken every minute until 36:00 minutes, when the calorimeter again reached a steady state, denoting the end of the "reaction" period. During the "after" period from 36:00 to 56:00 minutes, readings of the resistance of the platinum thermometer were taken every two minutes. After the end of the "after" period, the platinum thermometer was transferred from the calorimeter can to the jacket, and its resistance at the temperature of the jacket was measured.

The calculation of $\Delta R_{c}$, the corrected increase in temperature of the calorimeter system, expressed as the increase in resistance in ohms of the given platinum resistance thermometer at a mean temperature of $26.50^{\circ} \mathrm{C}$, as measured with the given resistance bridge, has been previously described [4]. The amount of electrical energy divided by the value of $\Delta R_{c}$ for the same experiment yields a value of $E_{s}$, the electrical energy equivalent of the calorimeter for the standard conditions.

5 The "temporary" settings are those in which the current flows through the automatic switch, and the "permanent" settings are those in which the current flows through switches which bypass the automatic switch. 


\section{DETERMINATION OF THE IGNITION ENERGY}

The energy added to the calorimeter by the heating and burning of the fuse wire was determined as previously described [4]. The standard process of ignition produced an increase of $0.000411 \mathrm{ohm}$ in the "temperature" of the standard calorimeter system. The fuse was a 5-cm length of "Parr" wire, No. 36 AWG, the "standard" weight of which was $0.00760 \mathrm{~g}$. An alternating current from a 24 -volt supply was used for the ignition.

\section{COMBUSTION EXPERIMENTS}

The procedure followed in performing a calorimetric combustion experiment is described in detail on pages 302 and 303 of reference [4].

\section{CORRECTION FOR THE FORMATION OF NITRIC ACID}

The value of $\Delta r_{n}$, which is the rise in temperature of the calorimeter system produced by the heat evolved in the formation of a small amount of nitric acid, according to the reaction

$$
\frac{1}{2} \mathrm{~N}_{2}(\mathrm{~g})+\frac{1}{2} \mathrm{H}_{2} \mathrm{O}(\mathrm{liq})+\frac{5}{4} \mathrm{O}_{2}(\mathrm{~g})=\mathrm{HNO}_{3}(\mathrm{aq})
$$

was calculated from the amount of nitric acid formed, using the value $57.8 \mathrm{int} . \mathrm{kj} / \mathrm{mole}$ for the heat evolved in the formation of dilute aqueous nitric acid in the bomb process. The procedure previously described [4] was followed.

\section{RESULTS OF THE PRESENT INVESTIGATION}

\section{EXPERIMENTS WITH ELECTRICAL ENERGY}

During the course of this extended investigation, three changes were made in the calorimeter system, and there were actually four slightly different calorimeter systems, $A, B_{1}, B_{2}$, and $C$, with $B_{1}$ and $B_{2}$ being essentially identical in energy equivalent. The changes consisted in replacing the bronze sleeve (having 10 setscrews, holding the head against the body of the bomb) with a stainless-steel sleeve (having 16 setscrews), the loosely fitting calorimeter heater with one tightly fitting on the bomb body, and platinum resistance thermometer No. 285,380 with No. 373,730 , as follows:

\begin{tabular}{|c|c|c|c|}
\hline System & Sleeve & Heater & Thermometer \\
\hline $\begin{array}{l}A_{-} \\
B_{1} \\
B_{2} \\
C_{-}\end{array}$ & $\begin{array}{l}\text { Bronze } \\
\text { Stainless steel } \\
- \text { do }_{2}\end{array}$ & $\begin{array}{l}\text { Loosely fitting } \\
\text { Tightly fitting }\end{array}$ & $\begin{array}{l}\text { No. } 285,380 \\
\text { Do. } \\
\text { Do. } \\
\text { No. } 373,730\end{array}$ \\
\hline
\end{tabular}

The results of the experiments with electrical energy on systems $A, B_{1}, B_{2}$, and $C$ are given in table 1 . The symbols given in the table are defined in the previous reports $[4,8,10]$. 
TABLE 1.-Experiments with electrical energy on calorimeter systems

A. SYSTEM $A$ (WITH LOOSELY FITTING HEATER)

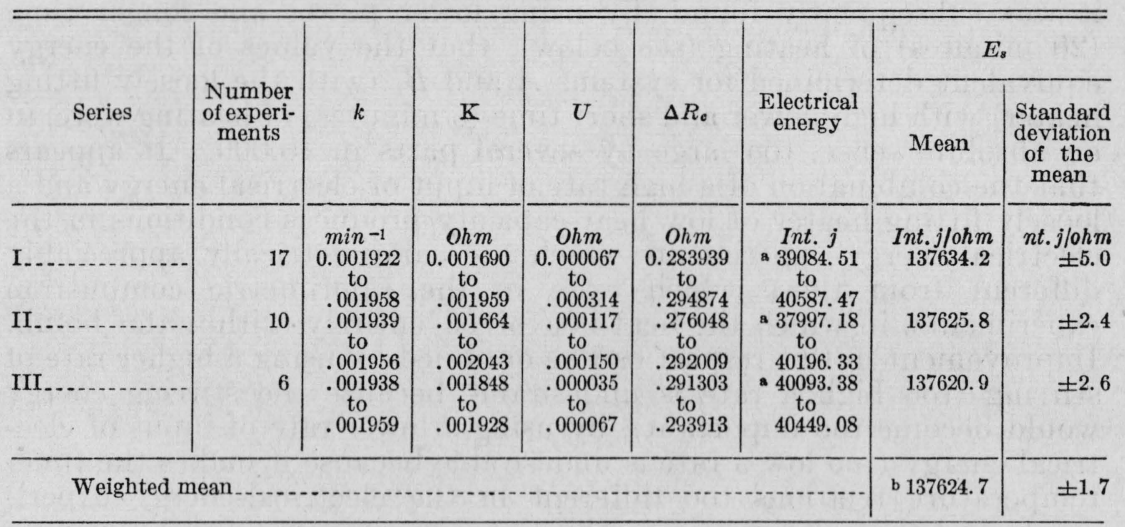

B. SYSTEM $B_{1}^{*}$ (WITH LOOSELY FITTING HEATER)

\begin{tabular}{|c|c|c|c|c|c|c|c|c|}
\hline I. . & 8 & $\begin{array}{c}0.001927 \\
\text { to } \\
.001955\end{array}$ & $\begin{array}{c}0.001729 \\
\text { to } \\
.001923\end{array}$ & $\begin{array}{c}0.000131 \\
\text { to } \\
.000154\end{array}$ & $\begin{array}{c}0.285673 \\
\text { to } \\
.294785\end{array}$ & $\begin{array}{c}39443.91 \\
\text { to } \\
40703.17\end{array}$ & b 138044.7 & \pm 3.2 \\
\hline
\end{tabular}

B. SYSTEM $B_{2}$ (WITH TIGHTLY FITTING HEATER)

\begin{tabular}{|c|c|c|c|c|c|c|c|c|}
\hline $\begin{array}{l}\text { •II_. } \\
\text { oIII. } \\
\text { 'IV.. }\end{array}$ & $\begin{array}{l}4 \\
4 \\
6\end{array}$ & $\begin{array}{c}0.001932 \\
\text { to } \\
.001945 \\
.001940 \\
\text { to } \\
.001946 \\
.001943 \\
\text { to } \\
.001949 \\
.001960 \\
\text { to } \\
.001987\end{array}$ & $\begin{array}{c}0.006607 \\
\text { to } \\
.006690 \\
.002012 \\
\text { to } \\
.002206 \\
.006471 \\
\text { to } \\
.006577 \\
.001385 \\
\text { to } \\
.002060\end{array}$ & $\begin{array}{c}0.000323 \\
\text { to } \\
.000371 \\
.000549 \\
\text { to } \\
.000579 \\
.001046 \\
\text { to } \\
.001168 \\
.000330 \\
\text { to } \\
.000581\end{array}$ & $\begin{array}{c}0.287110 \\
\text { to } \\
.289724 \\
.289845 \\
\text { to } \\
.297640 \\
.289570 \\
\text { to } \\
.290903 \\
.293368 \\
\text { to } \\
.304355\end{array}$ & $\begin{array}{c}\text { d } 39606.34 \\
\text { to } \\
39970.73 \\
\text { d } 39981.78 \\
\text { to } \\
41058.92 \\
\text { d } 39938.17 \\
\text { to } \\
40127.50 \\
\text { d } 40478.37 \\
\text { to } \\
41978.61\end{array}$ & $\begin{array}{l}137998.7 \\
137994.1 \\
137987.1 \\
137987.8\end{array}$ & $\begin{array}{l} \pm 4.2 \\
\pm 4.2 \\
\pm 4.7 \\
\pm 8.8\end{array}$ \\
\hline \multicolumn{7}{|c|}{ Weighted mean... } & 137993. 3 & \pm 2.4 \\
\hline
\end{tabular}

C. SYSTEM $C$ (WITH TIGHTLY FITTING HEATER)

\begin{tabular}{|c|c|c|c|c|c|c|c|c|}
\hline I. & 7 & $\begin{array}{c}0.001950 \\
\text { to } \\
.001959\end{array}$ & $\begin{array}{c}0.001928 \\
\text { to } \\
.002942\end{array}$ & $\begin{array}{c}0.000280 \\
\text { to } \\
.000364\end{array}$ & $\begin{array}{c}0.259366 \\
\text { to } \\
.295728\end{array}$ & $\begin{array}{c}35721.60 \\
\text { to } \\
40736.74\end{array}$ & 137717.4 & \pm 0.8 \\
\hline
\end{tabular}

a The time of input of electrical power was 300.00 seconds, with a current of 0.97 ampere.

b This value is used only for obtaining the ratio of the energy equivalents of systems $A$ and $B_{1}$.

- The rate of stirring of the calorimeter was $285 \mathrm{rpm}$ in series I, $400 \mathrm{rpm}$ in series II and III, and $350 \mathrm{rpm}$ in series IV.

d In series I and III, the time of input of electrical power was 1200.00 seconds, with a current of 0.48 amperes; in series II and IV, the time was 300.00 seconds, with a current of 0.97 ampere. 
The data given in table $1 \mathrm{~A}$ and $1 \mathrm{~B}_{1}$ yield a precise value for the ratio of the energy equivalents of calorimeter systems $A$ and $B_{1}$. However, it was subsequently found, by using lower power and longer time (20 minutes) of heating (see below), that the values of the energy equivalent determined for systems $A$ and $B_{1}$ (with the loosely fitting heater) with high power and short time (5 minutes) of heating were, in an absolute sense, too large by several parts in 10,000. It appears that the combination of a high rate of input of electrical energy and a loosely fitting heater of low heat capacity produces conditions in the electrical-energy experiments which are calorimetrically appreciably different from those which exist in the calorimetric combustion experiments, in which the heat is evolved entirely within the bomb. Improvement in this respect can be obtained by using a higher rate of stirring (too high a rate is undesirable because the stirring energy would become too important), by using a lower rate of input of electrical energy (too low a rate is undesirable because it makes the timetemperature relations too different in the electrical-energy experiments and the calorimetric combustion experiments), and by using a heater which fits tightly on the bomb body (which would permit a large part of the electrical energy to be taken up first by the bomb body, simulating a little more closely the conditions in the calorimetric combustion experiments). Accordingly, system $B_{1}$ was changed to system $B_{2}$ by replacing the loosely fitting heater with one fitting tightly on the bomb body. The systems $B_{1}$ and $B_{2}$ were identical in every way except for a smaller mass (about $14.5 \mathrm{~g}$ less) of copper used in making the tightly fitting heater. The equivalent of $14.5 \mathrm{~g}$ of copper was added to system $B_{2}$, making the energy equivalent of system $B_{2}$ exactly equal to that of system $B_{1}$.

The data in table $1 \mathrm{~B}_{2}$, giving the results of four different series of experiments, provide an accurate value for the energy equivalent of system $B_{2}$, and thus also of system $B_{1}$. The value, and standard deviation of the mean, for the energy equivalent of system $B_{2}\left(=B_{1}\right)$ is

$$
E_{s}\left(B_{2}\right)=137,993.3 \pm 2.4 \text { int. j/ohm. }
$$

In series $\mathrm{I}$ and III (in table $1 \mathrm{~B}_{2}$ ) the time of heating was 20 minutes, with a current of approximately 0.48 ampere; whereas in series II and IV the time of heating was 5 minutes, with a current of approximately 0.97 ampere. With the absolute value of the energy equivalent of system $B_{2}$ established from the experiments reported in table $1 \mathrm{~B}_{2}$, and with that for system $B_{1}$ taken (after appropriate adjustment) as equal to that of system $B_{2}$, the energy equivalent of system $A$ was calculated from the value for system $B_{2}$ and the ratio for systems $A$ and $B_{1}$ as given by the values in table $1 \mathrm{~A}$ and $1 \mathrm{~B}_{1}$. The value, and standard deviation of the mean, for the energy equivalent of system $A$ becomes

$$
E_{s}(A)=137,573.5 \pm 4.3 \text { int. } \mathrm{j} / \mathrm{ohm} \text {. }
$$

The data given in table $1 \mathrm{C}$ yield an accurate value for the energy equivalent of calorimeter system $C$ (in terms of its new thermometer) 
System $C$, as previously reported, differed from system $B_{2}$ only in the thermometer used. The value, and standard deviation of the mean, for the energy equivalent of system $C$ is

$$
E_{s}(C)=137,717.4 \pm 0.8 \text { int. } \mathrm{j} / \mathrm{ohm} .
$$

A number of experiments with benzoic acid [16] made on the three calorimeter systems yielded values for the ratios of their energy equivalent which were equal to the ratios below within their respective limits of uncertainty. Also, the value for the heat of combustion of benzoic acid under the standard conditions of the bomb process is in excellent agreement with the most recent value reported by Jessup [17]. The data of six experiments on system $A$, with a heating period of 20 minutes, yielded a value, and standard deviation of the mean, for the energy equivalent of system $A$ of $137,572.9 \pm 0.9$ int. $\mathrm{j} / \mathrm{ohm}$, which energy equivalent is essentially identical with the value given above for $E_{s}(A)$.

As it was found desirable to present the data of the combustion experiments (see next section) in terms of the final calorimeter system, $C$, the following relations were used to make the conversion:

$$
\begin{aligned}
& E_{s}(A)=0.998955 E_{s}(C) \\
& E_{s}(B)=1.002003 E_{s}(C) .
\end{aligned}
$$

The over-all uncertainty assigned to the value of the energy equivalent of calorimeter system $C$, in terms of which all the data are reported, was taken as twice the standard deviation of the mean of the least precise series of measurements (those of system $A$ ), \pm 0.006 percent, together with an estimated uncertainty of \pm 0.010 percent allowed for errors in calibration of the electrical measuring instruments, yielding, as the square root of the sum of the squares, \pm 0.012 percent as the over-all uncertainty for the experiments with electrical energy. The energy equivalent of system $C$, with its over-all uncertainty, was taken, therefore, as

$$
E_{s}(C)=137,717.4 \pm 16.5 \text { int. } \mathrm{j} / \mathrm{ohm} \text {. }
$$

\section{COMBUSTION EXPERIMENTS}

The results of the combustion experiments on $n$-pentane, $n$-hexane, $n$-heptane, $n$-octane, $n$-nonane, $n$-decane, $n$-dodecane, and $n$-hexadecane are given in table 2. The symbols at the heads of the columns are as previously defined $[4,8,10]$. For simplicity in presenting and handling the data, all the values of the constant $B$ are given in terms of the energy equivalent of system $C$, using the conversion factors given in the preceding section. 
TABLE 2.-Results of calorimetric combustion experiments on n-pentane, $n$-hexane, $n$-heptane, $n$-octane, $n$-nonane, $n$-decane, $n$-dodecane, and $n$-hexadecane, in the liquid state

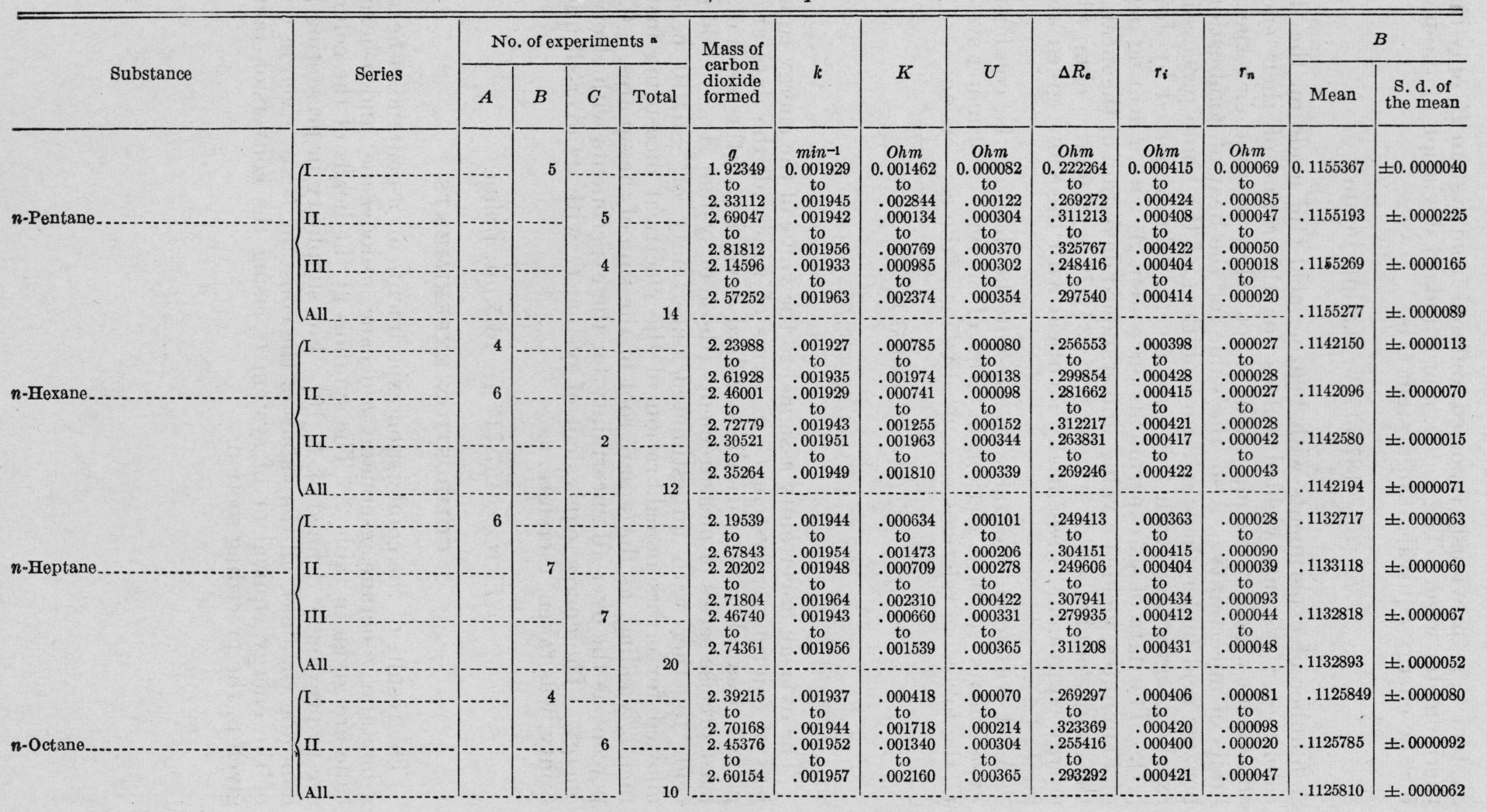




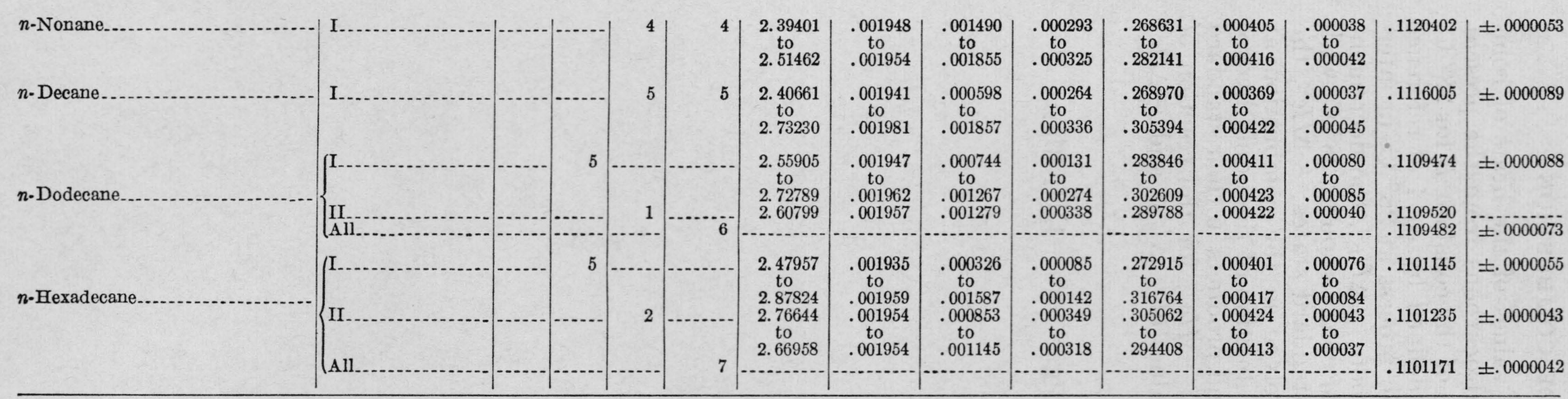

a The numbers in the columns labeled $A, B$, and $C$ indicate the number of experiments performed with calorimeter systems $A, B$, and $C$ (see section V-1, section VII-1, and table 1. 


\section{VALUES OF THE HEATS OF COMBUSTION}

In table 3 are presented the resulting values of the heats of combustion of the eight normal paraffin hydrocarbons from the present investigation. There are given the value of the constant $B$ for $28^{\circ} \mathrm{C}$, in ohms per gram of carbon dioxide, as defined by eq 4 of reference [4]; $-\Delta U_{B}$, the heat evolved in the bomb process at $28^{\circ} \mathrm{C}$, in international kilojoules per mole of hydrocarbon; $-\Delta U_{R}^{\circ}$, the decrement in internal energy for the ideal reaction of combustion at $28^{\circ} \mathrm{C}$, with all the reactants and products in their standard states; $-\Delta H c^{\circ}$, the decrement in heat content (or heat evolved in the combustion at constant pressure) for the reaction of combustion of the liquid hydrocarbon at $28^{\circ} \mathrm{C}$, with all the reactants and products in their standard states; and, finally, the same quantity, $-\Delta H c^{\circ}$, for the reaction of combustion at $25^{\circ} \mathrm{C}$. The foregoing values of $-\Delta U_{R}^{\circ}$ and $-\Delta H c^{\circ}$ apply to the reaction

$$
\mathrm{C}_{n} \mathrm{H}_{2 n+2} \text { (liq) }+\frac{3 n+1}{2} \mathrm{O}_{2} \text { (gas) }=n \mathrm{CO}_{2} \text { (gas) }+(n+1) \mathrm{H}_{2} \mathrm{O} \text { (liq) }
$$


TABLE 3.-Values of the heats of combustion

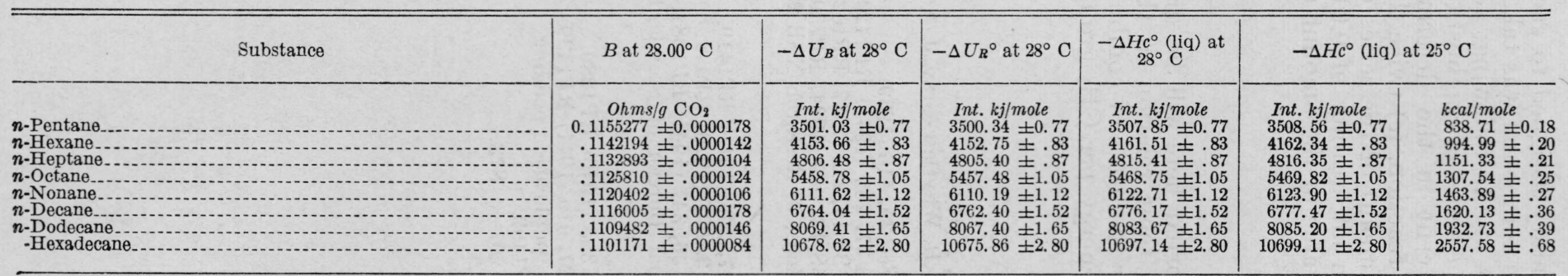


As stated in section III, the over-all uncertainty assigned to each final value of the heat of combustion of a given compound was taken as the square root of the sum of the squares of the following: $(a)$ Twice the standard deviation of the mean of the series of combustion experiments, $(b)$ an uncertainty of 0.010 percent in the determination of the absolute value of the amount of reaction, $(c)$ twice the standard deviation of the mean (or weighted mean) of the series of experiments with electrical energy, and $(d)$ an uncertainty of 0.010 percent in the determination of the absolute value of the amount of electrical energy.

\section{DISCUSSION}

The values of the heats of combustion reported here will be discussed in another report in connection with their relation to the existing data, the selection of "best" values for the heats of combustion, and the evaluation of the increment in energy per $\mathrm{CH}_{2}$ group, for the normal paraffin hydrocarbons.

\section{REFERENCES}

[1] E. F. Mueller and F. D. Rossini, Am. J. Phys. 12, 1 (1944).

[2] G. P. Baxter, M. Guichard, O. Hönigschmid, and R. Whytlaw-Gray, J. Am. Chem. Soc. 63, 845 (1941).

[3] F. D. Rossini and W. E. Deming, J. Wash. Acad. Sci. 29, 416 (1939).

[4] E. J. Prosen and F. D. Rossini, J. Research NBS 27, 289 (1941) RP1420.

[5] F. D. Rossini and J. W. Knowlton, J. Research NBS 19, 249 (1937) RP1024.

[6] E. F. Mueller and H. F. Stimson, J. Research NBS 13,699 (1934) RP739.

[7] N. S. Osborne, H. F. Stimson, and D. C. Ginnings, J. Research NSB 23, 197 (1939) RP1228.

[8] F. D. Rossini, BS J. Research 6, 1 (1931)RP259.

[9] F. B. Silsbee and F. J. Gross, J. Research NBS 27, 269 (1941) RP1419.

[10] J. R. Eckman and F. D. Rossini, BS J. Research 3, 597 (1929) RP111.

[11] $M$. Shepherd and H. W. Bailey, J. Research NBS 26, 347 (1941) RP1381.

[12] A. R. Glasgow, Jr., and F. D. Rossini, National Bureau of Standards. Unpublished.

[13] B. J. Mair, BS J. Research 9, 457 (1932) RP482.

[14] B. J. Mair and A. J. Streiff, J. Research NBS 24, 395 (1940) RP1289.

[15] E. J. Prosen and F. D. Rossini, J. Research NBS 27, 519 (1941) RP1439.

[16] E. J. Prosen and F. D. Rossini, J. Research NBS (publication pending).

[17] R. S. Jessup, J. Research NBS 29, 247 (1942) RP1499.

[18] E. B. Rosa and H. D. Babcock, Bul. BS 4, 121 (1907-8) S73.

Washington, June 10, 1944. 